\title{
Age-Related Weakening of Baroreflex-Mediated Sympathetic Activity in Spontaneously Hypertensive Rats in Response to Blood Pressure Reduction
}

\author{
Pablo Prados, Tomofumi Santa, Takeshi Fukushima, Hiroshi Homma, Chieko Kasai*, \\ Maria Antonia Martin**, Benito del Castillo**, and Kazuhiro Imai
}

\begin{abstract}
Nicardipine, a dihydropyridine type calcium channel blocker, was infused into 4-, 6-, and 23-wk-old spontaneously hypertensive (SH) and age-matched normotensive Wistar-Kyoto (WKY) rats (under sodium thiobutabarbital anesthesia and ventilation, $n=4$ ) through the left femoral vein, resulting in the reduction of blood pressure. In each rat, mean arterial blood pressure, heart rate, and the concentration of plasma catecholamines (CAs), norepinephrine (NE), and epinephrine (E) were concomitantly determined, and the correlations between these three variables were studied. During the infusion of nicardipine, the plasma concentration of CAs was measured with an automatic detection system in blood samples collected from the right femoral artery of each rat. The reduction in blood pressure induced by nicardipine brought about an increase in plasma CA levels. The blood pressure correlated well with the logarithm of plasma NE or $E$ concentration according to the formula $Y=-\alpha \log (X)+m(Y$, blood pressure; $X$, concentration of plasma $\mathrm{NE}$ or $\mathrm{E}$; $\alpha$, slope; and $m$, intercept). The slopes $(\alpha \mathrm{s})$ of 6-wk-old and 23-wk-old SH rats were significantly greater than those of aged-matched WKY rats, meaning that the increment in plasma CAs in response to a decrease in blood pressure was smaller in SH than in WKY rats of similar ages. However, no significant differences were found between the $\alpha \mathrm{s}$ of 4-wk-old SH and WKY rats. We conclude that the increment in the baroreflex-mediated sympathetic activity in response to a drop in blood pressure induced by nicardipine is similar or greater in prehypertensive $\mathrm{SH}$ than in normotensive WKY 4-wk-old rats, while the increment becomes smaller in SH rats with the onset of hypertension (6-wk-old rats), and is much less in fully hypertensive adult (23-wk-old) SH rats than in age-matched WKY rats. On the basis of these findings and previous data obtained by neurography, we conclude that plasma CAs can be used to evaluate baroreflex-mediated sympathetic activity countering the blood pressure reduction caused by calcium antagonists. (Hypertens Res 1998; 21: 147153)
\end{abstract}

Key Words: nicardipine, rat plasma catecholamines, blood pressure, baroreflex-mediated sympathetic activity, spontaneously hypertensive rat

Many papers have reported that plasma catecholamines (CAs) can be used to evaluate baroreflexmediated sympathetic activity, because circulating CAs consist mainly of CAs liberated from the synapses of sympathetic nerves in proportion to the degree of such activity (1-10). We showed for the first time that the blood pressure reduction caused by the continuous infusion of diltiazem, verapamil, or nicardipine in Sprague-Dawley (SD) rats correlated significantly with the increases in plasma norepinephrine (NE) and epinephrine (E) concentrations $(11,12)$. Further studies of diltiazem and nicardipine given by infusion to adult ( 23 to $28 \mathrm{wk}$ old) spontaneously hypertensive (SH) and agematched normotensive Wistar-Kyoto (WKY) rats revealed similar, close correlations in both strains (13). These findings showed the great contribution of baroreflex-mediated sympathetic activity to blood pressure regulation in $\mathrm{SD}, \mathrm{SH}$, and WKY rats, acting to raise the artificially diminished blood pressure to normal values. These results also revealed reduced sensitivity of the baroreflex-mediated sympathetic response in adult SH rats as compared with age-matched normotensive WKY rats once the chronic phase of hypertension is established (13). These data were obtained with the use of a fully-automated, highly-sensitive, selective system for the determination of plasma CAs, which requires only $25 \mu \mathrm{l}$ of rat plasma $(14,15)$.

Since the role of baroreflex-mediated sympathetic

From the Department of Bio-Analytical Chemistry, Graduate School of Pharmaceutical Sciences, The University of Tokyo, Tokyo, Japan, *Pharmacological Research Laboratory, Yamanouchi Seiyaku Co.,Ltd., Tsukuba, Japan, and ** Laboratorio de Técnicas Instrumentales, Facultad de Farmacia, Universidad Complutense de Madrid, Madrid, Spain. Address for Reprints: Prof. Kazuhiro Imai, Department of Bio-Analytical Chemistry, Graduate School of Pharmaceutical Sciences, The University of Tokyo, 7-3-1 Hongo, Bunkyo-ku, Tokyo 113-0033, Japan.

Received December 5, 1997; accepted in revised form May 18, 1998. 
activity in the development and maintenance of hypertension in $\mathrm{SH}$ rats remains controversial (16-21) and since increased sympathetic activity as well as high levels of plasma CAs have been suggested to be present in young $\mathrm{SH}$ rats (22), we further studied the evolution of baroreflex-mediated sympathetic activity in prehypertensive ( $4 \mathrm{wk}$ old), mildly hypertensive (6 wk old) and fully hypertensive (23 wk old) SH rats as compared with age-matched normotensive WKY rats.

\section{Methods}

\section{Reagents and Animals}

CAs (norepinephrine, NE; epinephrine, E; dopamine, DA; and $N$-methyl dopamine, $N$-MeDA) were purchased from Sigma (St Louis, MO, USA). Trifluoroacetic acid (TFA) was obtained from Pierce (Rockford, IL, USA). Ethylenediamine (ED), acetonitrile, ethanol, dioxane, ethyl acetate, and distilled water, all of high-performance liquid chromatography (HPLC) grade, were purchased from WAKO (Osaka, Japan). Hydrogen peroxide, bis[2-(3,6,9-trioxadecanyloxycarbonyl)-4-nitrophenyl] oxalate (TDPO), and thiobutabarbital sodium salt were also from WAKO. Sodium octanesulfonate and imidazole (zone-refined) were obtained from Tokyo Kasei (Tokyo, Japan). Heparin sodium salt was obtained from Nacalai Tesque Inc. (Kyoto, Japan). Nicardipine hydrochloride, a dihydropyridine type calcium antagonist, was kindly donated by Yamanouchi Seiyaku, Co., Ltd. (Ibaraki, Japan). Male WKY and SH rats were supplied by Charles River Japan (Shizuoka, Japan). The ages of the rats were 4,6 , and $23 \mathrm{wk}$. Commercially available $N$ MeDA was purified as described previously (13).

\section{Infusion of Nicardipine and Sample Collection and Preparation}

WKY and SH rats were anesthetized with sodium thiobutabarbital $(100 \mathrm{mg} / \mathrm{kg}$, intraperitoneally). Additional doses of the anesthetic $(20 \mathrm{mg} / \mathrm{kg})$ were injected after the operation and before the infusion of nicardipine. Rats were ventilated (60 strokes/min, 1 $\mathrm{ml} / 100 \mathrm{~g} /$ stroke) until the end of the experiment, using a Model SAR-830 ventilator (CWE Co., PA, USA). Nicardipine was dissolved in saline at a concentration of $3.27 \times 10^{-2} \mathrm{mg} / \mathrm{kg} / \mathrm{ml}$. The solution of nicardipine was infused into the rats through the left femoral vein with a Model CFV-3100 infusion pump (Nihon Kohden, Tokyo, Japan) at flow rates (volume $\mathrm{load} / \mathrm{min}$ ) of $5.1,10.3,20.6$, and 51.0 $\mu \mathrm{l} / \mathrm{min}$. In terms of nicardipine, these flow rates corresponded to infusion rates of $0.16,0.33,0.67$, and $1.67 \mu \mathrm{g} / \mathrm{kg} / \mathrm{min}$. Infusion was started $30 \mathrm{~min}$ after surgery. The duration of each infusion was $20 \mathrm{~min}$. Syringes containing the nicardipine solution were covered with aluminium foil during the infusion to prevent decomposition of nicardipine by light. Nicardipine was infused into $4 \mathrm{WKY}$ and $4 \mathrm{SH}$ rats of each age studied (4, 6, and $23 \mathrm{wk})$. As control, 4 WKY and $4 \mathrm{SH}$ rats of each age were given saline infusions at the same flow rates as nicardipine. Arterial blood pressure and heart rate were measured through the left femoral artery with a Model DTX disposable transducer (Spectramed Inc., Oxnard, CA, USA), which was connected to a Model AP$621 \mathrm{G}$ carrier amplifier for arterial blood pressure (Nihon Kohden) and a Model AT-601 G heart rate counter (Nihon Kohden), these variables were recorded on a Model WR-3701 recticorder (Graphtec, Tokyo, Japan).

Blood $(0.20 \mathrm{ml})$ was collected through a catheter implanted into the right femoral artery, 10 and 5 min before the infusion of nicardipine or saline, and 15 min after the beginning of each step of the infusion. Plasma was diluted with an equivalent volume of a sample dilution buffer, the composition of which was $10 \mathrm{mM}$ glutathione, $10 \mathrm{mM}$ citric acid, $0.1 \%$ Triton X-100, $100 \mathrm{mg} / \mathrm{l}$ EDTA, and $8 \mathrm{mM} N$ MeDA ( $\mathrm{pH} 4.5)$. Fifty-microliter aliquots of the diluted mixture were then subjected to a fully-automated HPLC analyzer for CAs with PO-CL detection (14).

\section{HPLC Detection System and HPLC Conditions}

The fully-automated system consisted of four HPLC pumps, an autosampler, a rotatory six-way valve, a ternary gradient unit, a precolumn and an analytical column, two rotatory mixing devices, a reaction coil in a thermostatically controlled bath, and a system controller, as described previously (15). The CA extraction and HPLC conditions were as follows: precolumn, SERUMOUT-CEX, $10 \times 4 \mathrm{~mm}$ i.d. (Sekisui Co., Osaka, Japan); buffer for delivering CAs in the precolumn, $10 \mathrm{mM}$ potassium phosphate buffer $(\mathrm{pH} 7.5) /$ ethanol $(92: 8, \mathrm{v} / \mathrm{v})$, flow rate $1.0 \mathrm{ml} / \mathrm{min}$; adsorption time in the precolumn, 2 min; eluent, 75 $\mathrm{mM}$ potassium acetate buffer $(\mathrm{pH} 3.2)$ /acetonitrile $(81.7: 4.3: 14, \mathrm{v} / \mathrm{v} / \mathrm{v})$ containing $7 \mathrm{mM}$ sodium octanesulfonate, flow rate $0.5 \mathrm{ml} / \mathrm{min}$; desorption time from the precolumn, 2 min; precolumn cleanup solution, 4\% phosphoric acid/acetonitrile (50 : $50, \mathrm{v} / \mathrm{v}$ ), flow rate $1.0 \mathrm{ml} / \mathrm{min}$; precolumn clean-up time, $5 \mathrm{~min}$; analytical column, Crestpack, $150 \times 4.6$ $\mathrm{mm}$ i.d. (Jasco Co., Tokyo, Japan); column oven temperature, $40^{\circ} \mathrm{C}$; fluorogenic reagent solution, $120 \mathrm{mM}$ ED and $175 \mathrm{mM}$ imidazole in acetonitrile/ ethanol/water $(85: 10: 5, \mathrm{v} / \mathrm{v} / \mathrm{v})$, flow rate $0.30 \mathrm{ml} /$ min; reaction coil, Teflon tube $15 \mathrm{~m} \times 0.5 \mathrm{~mm}$ i.d.; reaction temperature, $80^{\circ} \mathrm{C}$; and chemiluminogenic reaction solution, $0.25 \mathrm{mM}$ TDPO, $150 \mathrm{mM} \mathrm{H}_{2} \mathrm{O}_{2}$, and $110 \mathrm{mM}$ TFA in dioxane/ethyl acetate $(50: 50$, $\mathrm{v} / \mathrm{v}$ ), flow rate $1.4 \mathrm{ml} / \mathrm{min}$.

\section{Method of Statistical Analysis}

Means and standard errors of arterial blood pressure, heart rate, and plasma CA concentration and correlations between these variables were calculated with Student's $t$-test, as described previously (12, 13).

\section{Results}

Heart rate was not significantly altered during nicardipine infusion in $\mathrm{SH}$ rats $\left(\mathrm{SH}_{4 \mathrm{wk}}\right.$, from $438 \pm 28$ to $423 \pm 24$ beats/min; $\mathrm{SH}_{6 \mathrm{wk}}$, from $442 \pm 27$ to $432 \pm$ 23 beats/min; $\mathrm{SH}_{23 \mathrm{wk}}$, from $462 \pm 25$ to $451 \pm 19$ 
beats/min) or WKY rats $\left(\mathrm{WKY}_{4 \mathrm{wk}}\right.$, from $379 \pm 21$ to $373 \pm 18$ beats/min; $W_{K} Y_{6 \mathrm{wk}}$, from $392 \pm 29$ to $383 \pm 23$ beats/min; $W_{K Y_{23 w k}}$, from $401 \pm 20$ to 394 \pm 17 beats $/ \mathrm{min})$.

The continuous infusion of nicardipine resulted in a gradual decrease in mean arterial blood pressure in both $\mathrm{SH}$ rats $\left(\mathrm{SH}_{4 \mathrm{wk}}\right.$, from $116 \pm 3.8$ to $49 \pm 3.6$ $\mathrm{mmHg} ; \mathrm{SH}_{6 \mathrm{wk}}$, from $153 \pm 6.5$ to $60 \pm 3.2 \mathrm{mmHg}$; $\mathrm{SH}_{23 \mathrm{wk}}$, from $192 \pm 5.0$ to $78 \pm 4.2 \mathrm{mmHg}$ ) and WKY rats $\left(\mathrm{WKY}_{4 \mathrm{wk}}\right.$, from $88 \pm 5.8$ to $44 \pm 3.7$ $\mathrm{mmHg} ; \mathrm{WKY}_{6 \mathrm{wk}}$, from $107 \pm 4.3$ to $48 \pm 5.6$ $\mathrm{mmHg} ; \quad \mathrm{WKY}_{23 \mathrm{wk}}$, from $120 \pm 7.0$ to $52 \pm 3.8$ $\mathrm{mmHg})(n=4)$ and a concomitant gradual increase in plasma $\mathrm{NE}$ concentration $\left(\mathrm{SH}_{4 \mathrm{wk}}\right.$, from $1.12 \pm$ 0.20 to $9.84 \pm 1.32 \mathrm{pmol} / \mathrm{ml} ; \mathrm{SH}_{6 \mathrm{wk}}$, from $0.74 \pm$ 0.13 to $5.57 \pm 0.62 \mathrm{pmol} / \mathrm{ml} ; \mathrm{SH}_{23 \mathrm{wk}}$, from $0.28 \pm$ 0.03 to $1.36 \pm 0.23 \mathrm{pmol} / \mathrm{ml} ; \mathrm{WKY}_{4 \mathrm{wk}}$, from $0.38 \pm$ 0.12 to $1.26 \pm 0.18 \mathrm{pmol} / \mathrm{ml} ; \mathrm{WKY}_{6 \mathrm{wk}}$, from $0.36 \pm$ 0.09 to $1.70 \pm 0.31 \mathrm{pmol} / \mathrm{ml}$; WKY $23 \mathrm{wk}$, from $0.27 \pm$ 0.05 to $2.16 \pm 0.48 \mathrm{pmol} / \mathrm{ml})$. An increase in plasma E concentration was also associated with the decrease in blood pressure $\left(\mathrm{SH}_{4 \mathrm{wk}}\right.$, from $0.32 \pm 0.12$ to $9.79 \pm 0.88 \mathrm{pmol} / \mathrm{ml} ; \mathrm{SH}_{6 \mathrm{wk}}$, from $0.25 \pm 0.07$ to $5.58 \pm 0.49 \mathrm{pmol} / \mathrm{ml} ; \mathrm{SH}_{23 \mathrm{wk}}$, from $0.12 \pm 0.02$ to $0.91 \pm 0.07 \mathrm{pmol} / \mathrm{ml} ; \mathrm{WKY}_{4 \mathrm{wk}}$, from $0.15 \pm 0.03$ to $1.08 \pm 0.30 \mathrm{pmol} / \mathrm{ml} ; W_{K Y} Y_{6 \mathrm{wk}}$, from $0.18 \pm 0.04$ to $1.86 \pm 0.56 \mathrm{pmol} / \mathrm{ml} ; \mathrm{WKY}_{23 \mathrm{wk}}$, from $0.08 \pm 0.007$ to $1.23 \pm 0.41 \mathrm{pmol} / \mathrm{ml}$ ). As shown in Figs. 1 and 2, the decrease in mean arterial blood pressure correlated with the increase in the plasma NE or E concentration in both SH and WKY rats of the three age groups examined $(4,6$, and $23 \mathrm{wk})$. The relations among these variables were expressed as $Y=$ $-\alpha \operatorname{LOG}(X)+m$, where $Y$ is the mean arterial blood pressure; $X$, the concentration of plasma NE or $\mathrm{E} ; \alpha$, the slope; $m$, the intercept. As summarized in Tables 1 and 2, a strong correlation was observed between the decrease in blood pressure and the increase in plasma NE or E concentration.

The slopes $(\alpha \mathrm{S})$ for NE or E increased significantly with age in $\mathrm{SH}$ rats $\left[\mathrm{NE}, \mathrm{SH}_{23 \mathrm{wk}}(176.9)>\mathrm{SH}_{6 \mathrm{wk}}\right.$ $(106.4)>\mathrm{SH}_{4 \mathrm{wk}}(73.5)(p<0.01) ; \mathrm{E}, \mathrm{SH}_{23 \mathrm{wk}}(131.7)$ $\left.>\mathrm{SH}_{6 \mathrm{wk}}(67.9)>\mathrm{SH}_{4 \mathrm{wk}}(43.7)(p<0.01)\right]$, but did not change significantly with the age in WKY rats $\left[\mathrm{NE}, \mathrm{WKY}_{23 \mathrm{wk}}(77.5), \mathrm{WKY}_{6 \mathrm{wk}}(87.2)\right.$ and $\mathrm{WKY}_{4 \mathrm{wk}}$ (78.4); E, WKY $23 w \mathrm{wk}(58.1), \mathrm{WKY}_{6 \mathrm{wk}}(58.3)$, and $\left.\mathrm{WKY}_{4 \mathrm{wk}}(54.8)\right]$. A greater slope indicates a lower baroreflex sensitivity since it represents a smaller evoked rise in plasma CAs to counter the same reduction in blood pressure $(12,13)$.

\section{Discussion}

\section{Selection of Nicardipine}

Although nitroprusside or phenylephrine has been used to evaluate sympathetic nervous activity, in this study we used nicardipine, because we have already demonstrated for several calcium antagonists, including nicardipine, the existence of a significant correlation between the decrease in blood pressure and the increases in plasma NE and $\mathrm{E}$ concentrations in adult SD (12), SH, and WKY rats (23-wk-old) (13). Nicardipine was also used because it is one of the most widely used dihydropyridine type calcium antagonists clinically.

\section{Selection of the Anesthetic Agent}

We anesthetized the animals with sodium thiobutabarbital. In our previous work (13), we studied the influence of several anesthetic agents on heart rate, blood pressure, and plasma $\mathrm{NE}$ and $\mathrm{E}$ concentrations in adult WKY and $\mathrm{SH}$ rats. We concluded that sodium thiobutabarbital was the anesthetic of choice because it did not affect normal blood pressure or heart rate in the rats and because it provided stable baseline blood pressure and heart rate for at least $2 \mathrm{~h}$, enough time to carry out this type of experiment.

\section{Heart Rate}

We previously reported a slight increase in heart rate associated with infusion of nicardipine in SD rats anesthetized with sodium pentobarbital (12), which might contribute to maintaining the blood pressure and thereby attenuate the baroreflex-mediated sympathetic activity. However, in the present as well as in a previous study (13), infusion of nicardipine in SH and WKY rats under thiobutabarbital anesthesia was associated with no increase in heart rate in individual rats of either strain. The absence of increments in heart rate permits a more precise assessment of the inherent sensitivity of the baroreflex arc mediating sympathetic activity through blood vessels, except for those in the heart. The combined influence of artificial ventilation and thiobutabarbital anesthesia seem to have stabilized heart rate.

\section{Basal Plasma Levels of CAs in SH and WKY Rats} We observed that plasma NE and E concentrations were two to three times higher in 4-wk-old and 6wk-old SH rats than in age-matched WKY rats. In contrast, we observed similar basal plasma NE and E concentrations in adult ( $23 \mathrm{wk}$ old) rats of both strains. These results agree with the generally accepted notion that $\mathrm{CA}$ concentrations are higher in SH rats than in WKY rats only before the onset or during the early phases of hypertension (0-6 wk), whereas in the established phase of hypertension CA concentrations are similar or slightly lower in adult $\mathrm{SH}$ rats than in age-matched WKY rats $(6-10,13,22)$.

\section{Plasma NE Levels and Blood Pressure after Infusion of Nicardipine}

The strong correlation between the decrease in blood pressure and the increase in plasma NE concentration in both rat strains at all ages examined (4, 6, and 23 wk) (Fig. 1) shows that the baroreflexmediated sympathetic response remains sensitive through the 23 first wk of age.

\section{Plasma E Levels and Blood Pressure after Infusion of Nicardipine}

Some reports $(4,6)$ have suggested that plasma $\mathrm{E}$ levels do not markedly increase under normal physiological conditions to compensate for a decrease in blood pressure, and that the role of plasma $\mathrm{E}$ in the 

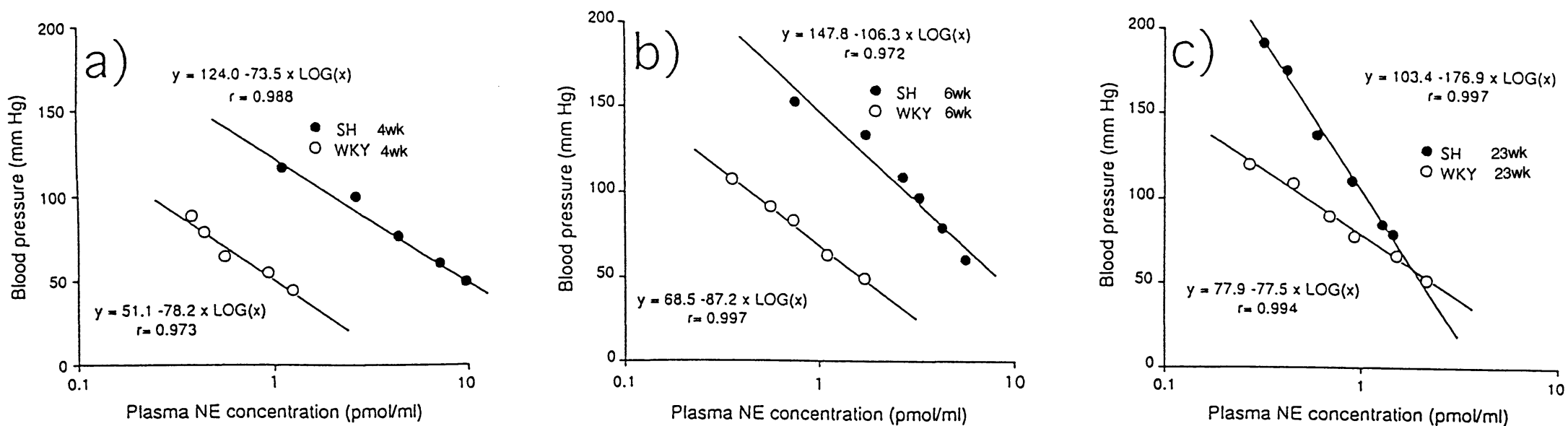

Fig. 1. Relation between mean arterial blood pressure and the logarithm of plasma NE concentration obtained with the infusion of nicardipine into SH and WKY rats 4 (a), 6 (b), or $23 \mathrm{wk}$ (c) of age. Values are the mean of four determinations (4 SH and $4 \mathrm{WKY}$ rats). The experimental conditions are described in the text.
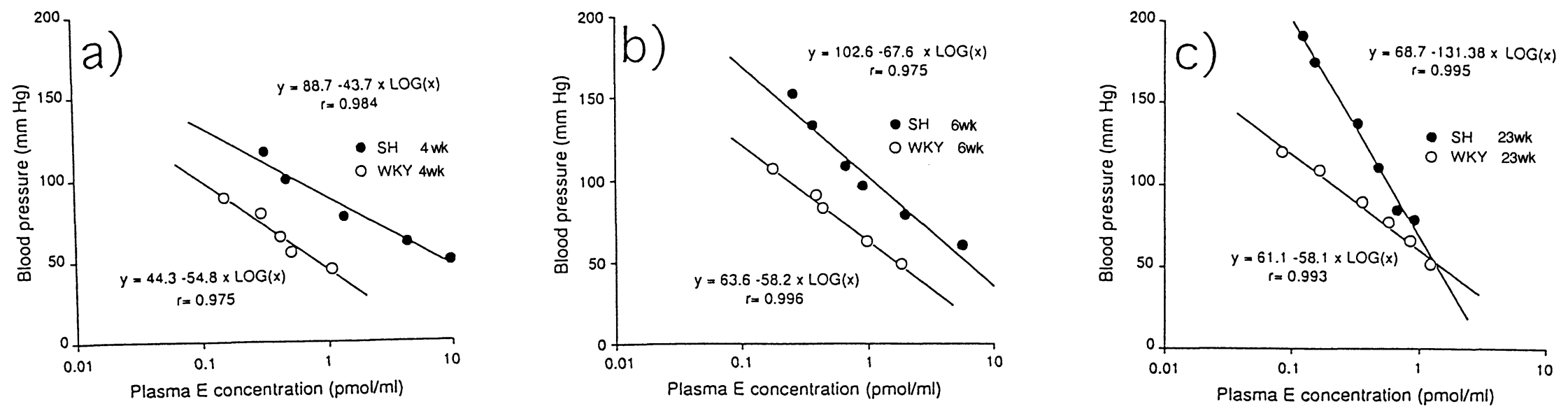

Fig. 2. Relation between mean arterial blood pressure and the logarithm of plasma $E$ concentration obtained with the infusion of nicardipine into SH and WKY rats 4 (a), 6 (b) or $23 \mathrm{wk}(\mathrm{c})$ of age. Values are the mean of four determinations (4 SH and $4 \mathrm{WKY}$ rats). The experimental conditions are described in the text. 
Table 1. Relation between Mean Arterial Blood Pressure and the Logarithm of Plasma NE Concentration $(n=4)$ after the Infusion of Nicardipine or Saline Solution into 4-, 6-, or 23-wk-old SH and WKY Rats

\begin{tabular}{|c|c|c|c|c|c|c|}
\hline & \multicolumn{3}{|c|}{ Nicardipine } & \multicolumn{3}{|c|}{ Control } \\
\hline & $23 \mathrm{wk}$ & $6 \mathrm{wk}$ & $4 \mathrm{wk}$ & $23 \mathrm{wk}$ & $6 \mathrm{wk}$ & $4 \mathrm{wk}$ \\
\hline \multicolumn{7}{|c|}{ SH Rats } \\
\hline$\alpha$ & $176.9 \pm 10.7$ & $106.4 \pm 5.2$ & $73.5 \pm 4.8$ & $11.3 \pm 4.5$ & $9.2 \pm 3.1$ & $-4.8 \pm 3.4$ \\
\hline$m$ & $103.4 \pm 2.3$ & $147.8 \pm 8.6$ & $123.9 \pm 6.4$ & $124.8 \pm 8.1$ & $126.0 \pm 4.8$ & $116.0 \pm 8.7$ \\
\hline$r$ & -0.994 & -0.972 & -0.988 & -0.378 & -0.428 & -0.592 \\
\hline \multicolumn{7}{|c|}{ WKY Rats } \\
\hline$\alpha$ & $77.5 \pm 4.3$ & $87.2 \pm 6.1$ & $78.4 \pm 5.2$ & $-9.5 \pm 3.2$ & $4.3 \pm 1.6$ & $17.6 \pm 4.2$ \\
\hline$m$ & $77.8 \pm 1.4$ & $68.5 \pm 2.3$ & $51.1 \pm 2.7$ & $92.6 \pm 4.8$ & $78.4 \pm 5.9$ & $56.3 \pm 4.8$ \\
\hline$r$ & -0.994 & -0.997 & -0.973 & -0.673 & -0.329 & -0.436 \\
\hline
\end{tabular}

Values are means \pm SD. Comparisons of the slopes $(\alpha \mathrm{s})$ of the 4-, 6-, and 23-wk-old rats $(n=4)$ with Student's $t$-test resulted in the following: SH rats, nicardipine $>$ control $(p<0.01)$ for the 23-, 6-, and 4-wk-old rats; comparison between ages (nicardipine): $\mathrm{SH}_{23 \mathrm{wk}}>\mathrm{SH}_{6 \mathrm{wk}}(p<0.01), \mathrm{SH}_{6 \mathrm{wk}}>\mathrm{SH}_{4 \mathrm{wk}}(p<0.01)$. WKY rats, nicardipine $>$ control $(p<0.01)$ for the 23-, 6-, and 4-wk-old rats; comparison between ages (nicardipine): $\mathrm{WKY}_{23 \mathrm{wk}}=\mathrm{WKY}_{6 \mathrm{wk}}(p<0.01 ; p<0.05)$, WKY $6 \mathrm{wk}=$ $\mathrm{WKY}_{4 \mathrm{wk}}(p<0.01 ; p<0.05)$. Comparison of $\alpha \mathrm{s}$ between $\mathrm{SH}$ and WKY rats (nicardipine): $\mathrm{SH}_{23 \mathrm{wk}}>\mathrm{WKY} 23 \mathrm{wk}(p<0.01)$, $\mathrm{SH}_{6 \mathrm{wk}}>\mathrm{WKY}_{6 \mathrm{wk}}(p<0.01), \mathrm{SH}_{4 \mathrm{wk}}=\mathrm{WKY}_{4 \mathrm{wk}}(p<0.01 ; p<0.05)$.

Table 2. Relation between Mean Arterial Blood Pressure and the Logarithm of Plasma E Concentration $(n=4)$ after the Infusion of Nicardipine or Saline Solution into 4, 6, or 23-wk-old SH and WKY Rats

\begin{tabular}{|c|c|c|c|c|c|c|}
\hline & \multicolumn{3}{|c|}{ Nicardipine } & \multicolumn{3}{|c|}{ Control } \\
\hline & $23 \mathrm{wk}$ & $6 \mathrm{wk}$ & $4 \mathrm{wk}$ & 23 wk & $6 \mathrm{wk}$ & $4 \mathrm{wk}$ \\
\hline \multicolumn{7}{|c|}{ SH Rats } \\
\hline$\alpha$ & $131.7 \pm 6.3$ & $67.9 \pm 4.2$ & $43.7 \pm 3.9$ & $21.4 \pm 6.7$ & $12.1 \pm 6.2$ & $-2.3 \pm 4.2$ \\
\hline$m$ & $68.7 \pm 3.5$ & $103.5 \pm 4.7$ & $88.7 \pm 4.1$ & $50.2 \pm 4.6$ & $83.2 \pm 4.3$ & $76.1 \pm 2.8$ \\
\hline$r$ & -0.995 & -0.975 & -0.983 & -0.556 & -0.328 & -0.438 \\
\hline \multicolumn{7}{|c|}{ WKY Rats } \\
\hline$\alpha$ & $58.1 \pm 3.4$ & $58.3 \pm 3.1$ & $54.8 \pm 3.4$ & $18.1 \pm 4.2$ & $12.3 \pm 3.1$ & $6.9 \pm 2.3$ \\
\hline$m$ & $61.1 \pm 1.9$ & $63.7 \pm 3.1$ & $44.3 \pm 3.6$ & $48.4 \pm 6.2$ & $54.3 \pm 7.2$ & $49.3 \pm 5.9$ \\
\hline$r$ & -0.993 & -0.995 & -0.975 & -0.456 & -0.321 & -0.689 \\
\hline
\end{tabular}

Values are means \pm SD. Comparisons of the slopes $(\alpha \mathrm{s})$ of the 4-, 6-, and 23-wk-old rats $(n=4)$ with Student's $t$-test resulted in the following: SH rats, nicardipine $>$ control $(p<0.01)$ for the 23-, 6-, and 4-wk-old rats; comparison between ages (nicardipine): $\mathrm{SH}_{23 \mathrm{wk}}>\mathrm{SH}_{6 \mathrm{wk}}(p<0.01), \mathrm{SH}_{6 \mathrm{wk}}>\mathrm{SH}_{4 \mathrm{wk}}(p<0.01)$. WKY rats, nicardipine $>$ control $(p<0.01)$ for the 23-, 6-, and 4-wk-old rats; comparison between ages (nicardipine): $\mathrm{WKY}_{23 \mathrm{wk}}=\mathrm{WKY}_{6 \mathrm{wk}}(p<0.01 ; p<0.05)$, WKY $6 \mathrm{wk}=$ $\mathrm{WKY}_{4 \mathrm{wk}}(p<0.01 ; p<0.05)$. Comparison of the $\alpha \mathrm{s}$ between $\mathrm{SH}$ and WKY rats (nicardipine): $\mathrm{SH}_{23 \mathrm{wk}}>\mathrm{WKY} 23 \mathrm{wk}(p<$ $0.01), \mathrm{SH}_{6 \mathrm{wk}}>\mathrm{WKY}_{6 \mathrm{wk}}(p<0.01), \mathrm{SH}_{4 \mathrm{wk}}<\mathrm{WKY}_{4 \mathrm{wk}}(p<0.01)$

control of blood pressure is negligible. On the contrary, our present data on increased plasma E concentration in response to blood pressure reduction (Fig. 2) show that in both $\mathrm{SH}$ and WKY rats of 4, 6 , and 23 wk of age the sympathetic nervous system also stimulates the adrenomedullary secretion of $E$ to help maintain the blood pressure at normal levels, as we reported previously for adult (23-wkold) SD rats (12), and SH and WKY rats (13).

Evolution of Baroreflex Function with Age in SH and WKY Rats

A comparison between age-matched $\mathrm{SH}$ and WKY rats (Tables 1 and 2) showed that the slopes $(\alpha$ values) of the curves of blood pressure vs. the logarithm of plasma $\mathrm{NE}$ in prehypertensive $\mathrm{SH}_{4 \mathrm{wk}}$ (73.5) and normotensive $\mathrm{WKY}_{4 \mathrm{wk}}(78.4)$ rats were not significantly different $(p<0.01 ; p<0.05)$, while the slope for $\mathrm{E}$ was significantly smaller in $\mathrm{SH}_{4 \mathrm{wk}}$ (43.7) than in $\mathrm{WKY}_{4 \mathrm{wk}}$ rats $(54.8)(p<0.01)$. These data indicate that there is no difference in the baroreflex mediated release of NE between 4-wkold SH rats and age-matched WKY rats, whereas there is greater stimulation of $E$ release from the adrenal glands in SH rats. This apparent difference in sympathetic nervous system activity was restricted to 4-wk-old prehypertensive $\mathrm{SH}$ rats. In contrast, the slopes for both NE and E were significant- 
ly greater in mildly hypertensive, 6-wk-old $\mathrm{SH}$ rats than in age-matched WKY rats $\left[\mathrm{NE}, \mathrm{SH}_{6 \mathrm{wk}}(106.4)\right.$ $>\mathrm{WKY}_{6 \mathrm{wk}}(87.2) \quad(p<0.01) ; \mathrm{E}, \quad \mathrm{SH}_{6 \mathrm{wk}}(67.9)>$ $\left.\mathrm{WKY}_{6 \mathrm{wk}}(58.3)(p<0.01)\right]$. Finally, the differences were greatest between fully-hypertensive, 23-wk-old $\mathrm{SH}$ rats and age-matched $\mathrm{WKY}$ rats $\left[\mathrm{NE}, \mathrm{SH}_{23 \mathrm{wk}}\right.$ $(176.9)>\mathrm{WKY}_{23 \mathrm{wk}}(77.5) \quad(p<0.01) ; \quad \mathrm{E}, \quad \mathrm{SH}_{23 \mathrm{wk}}$ $(131.7)>$ WKY $\left._{23 \mathrm{wk}}(58.1)(p<0.01)\right]$.

A number of studies have assessed the influence of age and hypertension on the baroceptor reflex. In most, sympathetic nerve activity was evaluated on the basis of the strength of impulses in postganglionic neurons. In the present and previous studies of 4-, 6- and 23-wk old-SH rats (13), we measured plasma catecholamines released from nerve endings as an index of baroreflex-mediated sympathetic activity. Our data indicate that in $\mathrm{SH}$ rats there is a gradual reduction in baroreflex-mediated sympathetic activity, evident at $6 \mathrm{wk}$ of age concomitant with the onset of hypertension and associated with the increase in blood pressure with the age, i.e., with the development and establishment of hypertension. In normotensive WKY rats, inherent baroreflexmediated sympathetic activity is apparently unaltered at least through the 23 first wk of age. Our data agree with the previous findings obtained by neurography (17), indicating that the baroceptor sensitivity (expressed by mean arterial blood pressure) to the sympathetic nerve activity (expressed by mean renal activity) in $\mathrm{SH}$ rats of different ages (12 to 52 wk old) decreases with age, while the sympathetic nerve activity increases with age. Similar results were also recently obtained neurographically in $\mathrm{SH}$ rats $(10,28$, and $36 \mathrm{wk}$ old) (23). These studies demonstrate that plasma catecholamines can be used to evaluate changes in baroreflex-mediated sympathetic activity in response to the blood pressure reduction caused by calcium antagonists, although further investigations of other agents, such as nitroprusside, should be done to provide more information on this issue.

Available data do not allow us to determine whether the attenuation of baroreflex activity in $\mathrm{SH}$ rats is genetically controlled or whether such attenuation after the development of hypertension in $\mathrm{SH}$ rats results from a biological homeostatic mechanism attempting to counter the rise in blood pressure. To clarify this issue, further studies of newborn $\mathrm{SH}$ rats given nicardipine throughout their life are necessary. If weakening of baroreflex sensitivity is genetically determined, it would occur even when the development of hypertension is prevented by the administration of nicardipine to newborn $\mathrm{SH}$ rats. If attenuation of baroreflex sensitivity is caused by continuous adaptation to the development of hypertension, SH rats would have similar sympathetic activity as normotensive WKY rats for the duration of their life. The early start of treatment with antihypertensive agents such as trichloromethiazide, atenolol, nicardipine, and enalapril in $\mathrm{SH}$ rats $(10$ wk old) has been shown to improve baroceptormediated reflex function at $36 \mathrm{wk}$ of age (23). Moreover, further studies assessing the response to the discontinuance of treatment are required.

\section{Acknowledgements}

We thank Dr. C.K. Lim for his generous advice on the preparation of the manuscript.

\section{References}

1. Arnolda L, Minson J, Kapoor V, Pilowsky $\mathrm{P}$, Llewellyn-Smith I, Chalmers J: Amino acid neurotransmitters in hypertension. Kidney Int 1992; 41 (Suppl 37): S2-S7.

2. Micalizzi ER, Pals DT: Evaluation of plasma norepinephrine as an index of sympathetic neuron function in the concious, unrestrained rat. Life Sci 1979; 24: 2071-2076.

3. Agabiti-Rosei E, Alicandri C, Fariello R, Muiesan $\mathrm{G}$ : Catecholamines and haemodynamics in fixed essential hypertension. Clin Sci 1979; 57: 193s-196s.

4. Watson RD, Hamilton CA, Reid JL, Littler WA: Changes in plasma norepinephrine, blood pressure and heart rate during physical activity in hypertensive man. Hypertension 1979; 1: 341-348.

5. Yamaguchi I, Kopin IJ: Plasma catecholamine and blood pressure responses to sympathetic stimulation in pithed rats. Am J Physiol 1979; 237: H305-H310.

6. Goldstein DS, McCarty R, Polinsky RJ, Kopin IJ: Relationship between plasma norepinephrine and sympathetic neural activity. Hypertension 1983; 5: 552-559.

7. Yamori Y: Contribution of cardiovascular factors to the development of hypertension in spontaneously hypertensive rats. Jpn Heart J 1974; 15: 194-196.

8. Nagaoka A, Lovenberg W: Plasma norepinephrine and dopamine- $\beta$-hydroxylase in genetic hypertensive rats. Life Sci 1976; 19: 29-34.

9. Palermo A, Constantini C, Mara G, Libretti A: Role of sympathetic nervous system in spontaneous hypertension: changes in central adrenoceptors and plasma catecholamine levels. Clin Sci 1981; 61: 195s-198s.

10. De Champlain J, Farley L, Cousineau D, Van Ameringen MR: Circulating catecholamine levels in human and experimental hypertension. Circ Res 1976; 38: 109-114.

11. Higashidate S, Imai K, Prados P: Relations between blood pressure and plasma norepinephrine concentrations after administration of diltiazem to rats: HPLCperoxyoxalate chemiluminescence determination on an individual basis. Biomed Chromatogr 1994; 8: 1921.

12. Imai K, Higashidate $\mathrm{S}$, Prados $\mathrm{P}$, Santa $\mathrm{T}$, AdachiAkahane S, Nagao T: Relation between blood pressure and plasma catecholamine concentration after administration of calcium antagonists to rats. Biol Pharm Bull 1994; 17: 907-910.

13. Prados P, Santa T, Homma H, et al: Comparison of the sympathetic nervous system activity between spontaneously hypertensive and Wistar-Kyoto rats to respond to blood pressure reduction. Biol Pharm Bull 1997; 20: 341-344.

14. Higashidate S, Imai K: Determination of femtomol concentrations of catecholamines by high-performance liquid chromatography with peroxyoxalate chemiluminescence detection. Analyst 1992; 117: 18631868.

15. Prados $\mathrm{P}$, Higashidate $\mathrm{S}$, Imai $\mathrm{K}$ : A fully automated HPLC method for the determination of catecholamines in biological samples utilizing ethylenediamine condensation and peroxyoxalate chemiluminescence detection. Biomed Chromatogr 1994; 8: 1-8. 
16. Koepke JP, Di Bona GF: High sodium intake enhances renal nerve and antinatriuretic responses to stress in spontaneously hypertensive rats. Hypertension 1985; 7: 357-363.

17. Judy WV, Watanabe AM, Henry DP, Besh HR, Murphy WR, Hockel GM: Sympathetic nerve activity: role in regulation of blood pressure in spontaneously hypertensive rat. Circ Res 1976; 38 (Suppl II): II21-II29.

18. Hallback M, Folkow B: Cardiovascular responses to acute mental stress in spontaneously hypertensive rats. Acta Physiol Scand 1974; 90: 684-698.

19. De Champlain J, Van Ameringen MR: Regulation of blood pressure by sympathetic nerve fibers and adrenal medulla in normotensive and hypertensive rats. Circ Res 1972; 31: 617-628.
20. Lockette W, Otsuka Y, Carretero O: The loss of endothelium-dependent vascular relaxation in hypertension. Hypertension 1986; 8 (Suppl II): 61-66.

21. Luscher TF, Vanhoutte PM: Endothelium-dependent contractions to acetylcholine in the aorta of the spontaneously hypertensive rat. Hypertension 1986; 8: 344-348.

22. Tsuda K, Kusuyama Y, Hano T, Kuchii M, Nishio I, Masuyama Y: Neurotransmitter release and vascular reactivity in spontaneously hypertensive rats. Jpn Circ J 1984; 48: 1263-1269.

23. Kumagai K, Suzuki H, Ichikawa M, et al: Comparison of early and late start of antihypertensive agents and baroreceptor reflexes. Hypertension 1996; 27: 209-218. 